\title{
Tornar-se Terapeuta Corporal: a Trajetória Social Como Processo de "Autoconstrução"*
}

JANE A. RUSSO**

Este trabalho trata do modo como se constituiu e se autodefiniu um grupo profissional: os terapeutas corporais. Inicialmente, é necessário circunscrever com mais clareza o que comumente se chama 'terapias corporais'.

As terapias corporais passaram, nos últimos dez anos, por um processo de ampla difusão social. É possível inseri-las no bojo da difusão mais ampla das chamadas 'práticas alternativas', entre as quais se incluem medicinas 'paralelas' (como a homeopatia), técnicas de tratamento 'orientais' (como a acupuntura, o shiatsu e o do-in), técnicas de 'conscientização' corporal (como a anti-ginástica e os mais variados tipos de expressão corporal através da dança, do teatro etc), além de um sem-número de práticas que podem ser definidas como esotéricas ou místicas. Dentro desse complexo alternativo, as terapias corporais se apresentam como um recorte específico, embora certamente compartilhem diversas de suas características mais gerais - como, por exemplo, o

\footnotetext{
* Este artigo baseia-se em um dos capítulos da minha tese de doutorado, a ser apresentada ao Programa de Pós-Graduação em Antropologia Social do Museu Nacional/UFRJ, sob orientação do prof. Gilberto Velho. Agradeço a Margareth de Almeida Gonçalves, que discutiu comigo a primeira versão do trabalho, apresentando sugestões valiosas.

** Professora do Programa de Pós-Graduação em Psiquiatria e Saúde Mental do Instituto de Psiquiatria/UFRJ.
} 
uso das noções de 'natureza' e 'energia'. Minha investigação deixa de lado o que aproxima as terapias corporais e as demais práticas alternativas, de modo a enfatizar exatamente a especificidade daquelas: sua inserção no campo das práticas psicológicas e, como consequiência, o fato de constituírem uma possibilidade ocupacional para os profissionais que compõem a área 'psi' médicos e, sobretudo, psicólogos. Evidentemente, como discutirei no decorrer do trabalho, o estabelecimento de fronteiras entre o que é ou não terapia corporal faz parte da própria constituição do campo - isto é, da própria questão de que irei tratar.

As terapias corporais, como o nome indica, se caracterizam por um trabalho no corpo e com o corpo. Calcadas em maior ou menor grau na teoria reichiana, ${ }^{1}$ têm como fundamento a idéia de que os conflitos psicológicos se enraízam no corpo, expressando-se através de determinadas posturas, de tensões e espasmos musculares e de doenças somáticas. Disto decorre a crença de que não só é possível, mas necessário, trabalhar diretamente sobre o corpo para resolver queixas, problemas e doenças de ordem psicológica. Isto é, são terapias que partem do princípio de que o psicológico é corporal.

As terapias corporais costumam ser designadas pelo público leigo como 'bioenergética'. Estaé, porém, apenas uma das 'correntes' existentes no campo - talvez a que tenha conhecido a maior popularidade. Outras técnicas 'neoreichianas, 2 que influenciaram bastante o movimento das terapias corporais no Rio de Janeiro foram a biossíntese (criada por David Boadella) e a massagem biodinâmica (criada por Gerda Boyesen).

Seguindo o argumento desenvolvido por Robert Castel em La gestion des risques, consideramos que o intenso florescimento das terapias corporais no meio 'psi' carioca deve ser compreendido como parte do processo de difusão da psicanálise, que o precedeu no tempo. As terapias corporais surgiram e se desenvolveram no cenário 'psi' ocupando uma espécie de vazio deixado pela psicanálise, que se retraía - um refluxo comandado pela preocupação dos psicanalistas com a possível descaracterização de sua prática que, com a difusão, se vulgarizava excessivamente.

1 De Wilhelm Reich, psicanalista excluído da Sociedade Psicanalítica Internacional em 1934 por divergir da teoria e da prática freudianas. A partir de seus achados, cria um novo tipo de terapia: a 'vegetoterapia', que posteriormente, com a descoberta de 'energia orgônica', passa a denominar 'orgonoterapia'

2 A designação 'neo-reichiano' refere-se a técnicas terapêuticas que se baseiam de alguma forma na teoria reichiana, mas não seguem estritamente os preceitos da orgonoterapia. 
A intensa difusão social da psicanálise nos anos 70 na cidade do Rio de Janeiro é fato razoavelmente conhecido e estudado entre nós. Também é conhecido o monopólio mantido pelos médicos psiquiatras sobre o título legítimo de psicanalista, outorgado pelas sociedades 'oficiais'. ${ }^{3}$

Uma consciência importante do processo de difusão da psicanálise foi sua penetração - promovida pelos próprios psiquiatras-psicanalistas - entre os profissionais que gravitavam em torno da psiquiatria: assistentes sociais, terapeutas ocupacionais e, sobretudo, psicólogos. Estes se faziam psicanalisar, trabalhavam orientados pela teoria psicanalítica, mas não podiam se intitular psicanalistas. Esta situação, evidentemente problemática, acaba produzindo uma tensão intolerável, que, com o tempo, se transforma numa pressão cada vez mais forte contra o monopólio mantido pelas sociedades 'oficiais'.

Essa tensão se resolve, por assim dizer, no final dos anos 70, mas em especial durante os anos 80 , com o surgimento de grande número de instituições de formação independentes da International Psychoanalytical Association (IPA), que buscam legitimar-se na teoria lacaniana. É esta que, com sua ácida crítica à burocratização da IPA, abre as portas para a formação 'leiga'. Longe estamos, porém, de uma democratização radical do acesso ao título de psicanalista. O lacanismo, ao mesmo tempo em que defende a 'análise leiga', investe com o mesmo ardor contra a popularização e a conseqüente vulgarização da psicanálise.

Se as sociedades vinculadas à IPA restringiam o acesso ao título através da exigência de um diploma em medicina, as novas sociedades lacanianas vão restringi-lo através de exigências de outra ordem. Trata-se, desta feita, não somente de compreender uma teoria extremamente sofisticada, como também de manejar com suficiente destreza seus conceitos, de modo a produzir trabalhos que atestem essa compreensão e essa destreza. A barreira, antes visível -

3 As duas sociedades de formação fundadas em 1955 e 1957, filiadas à (e patrocinadas pela) International Psychoanalytical Association, conhecida pela sigla 'IPA'. As outras instituições de formação até então existentes eram o Instituto de Medicina Psicológica (criado ainda na década de 1950), o Círculo Psicanalítico do Rio de Janeiro (criado em 1969) e a Sociedade de Psicologia Clínica do Rio de Janeiro (fundada em 1971). Todas aceitavam não-médicos para formação, mas não rivalizavam com o prestígio das duas sociedades 'oficiais'.

4 Estou resumindo aqui um processo bem mais complexo, exemplarmente analisado por Ana Cristina Figueiredo (ver FIGUEIREDO A.C., "A difusão do movimento psicanalítico no Rio de Janeiro e seus efeitos sobre a formação profissional”, em Psicologia Clínica, PósGraduação e Pesquisa, vol. 1, n. 1, Rio de Janeiro, PUC/RJ, 1986; e FIGUEIREDO A.C., "O movimento psicanalítico no Rio de Janeiro na década de 70", em BIRMAN J. (org.). Percursos na historia da psicanálise. Rio de Janeiro, Taurus, 1988). 
ser ou não médico - é transposta para o terreno invisível da sofisticação intelectual e teórica. ${ }^{5}$

Os mesmos anos 80 assistem ao surgimento e à proliferação de um sem-número de práticas e terapias alternativas, entre as quais se destacam as terapias corporais. Robert Castel, analisando o que começava a ocorrer na França, fala na 'era da pós-psicanálise': 'L'aprés-psychanalyse, ce n'est pas la fin de la psychanalyse, mais la fin du contrôle par la psychanalyse du processus de diffusion de la culture psychologique dans la societé. ${ }^{6}$ Mais adiante o autor aponta o desequilíbrio entre "une base étroite de pratiques ortodoxes et des productions qui le sont de moins en moins" e afirma: "il devient patent que les instances de légitimation du milieu psychanalytique ne peuvent plus contrôler l'emsemble de ce processus de diffusion". ${ }^{7} \mathrm{O}$ argumento de Castel é que o intenso florescimento das 'terapias pós-psicanalíticas' é um produto bastardo ${ }^{8}$ da difusão da psicanálise. $O$ movimento que assistimos no Rio de Janeiro, no decorrer da década de 80, parece corroborar esse argumento.

Num processo aparentemente complementar, quando a tensão entre médicos e leigos se resolve através de uma crítica das reinterpretações 'medicalizantes' da psicanálise e de uma conseqüente volta à ortodoxia da relação dual, assiste-se a uma intensa expansão das terapias corporais, no bojo de todo um movimento de práticas e crenças alternativas. No momento em que a teoria psicanalítica, através do lacanismo, se volta para a palavra como via principal de acesso ao inconsciente, expande-se em torno da psicanálise um arco cada vez mais amplo de práticas que têm no corpo seu ponto principal de intervenção. A crítica à popularização da psicanálise, o retorno à ortodoxia freudiana, nada disso atingia mais esse amplo círculo de práticas e terapias pouco ortodoxas que, tendo se constituído nas margens da difusão da psicanálise, não dependiam mais dela.

Quem são esses profissionais que, certamente atraídos para a órbita 'psi' a partir da difusão psicanalítica, são ao mesmo tempo excluídos do hard core,

5 Desenvolvi esse argumento em dois trabalhos anteriores: RUSSO J.A., "A reorientação do campo psicanalítico nos anos 80", in Jornal Brasileiro de Psiquiatria, 39(6), 1990; e RUSSO J.A., "O lacanismo e o campo psicanalítico no Rio de Janeiro", in ROPA D. (org.), Anuário Brasileiro de Psicanálise. Rio de Janeiro, Relume-Dumará, 1991.

6 CASTEL R., La gestion des risques. Paris, Minuit, 1981, p. 155.

7 CASTEL R., ibidem, p. 161.

8 Face aos herdeiros legítimos da psicanálise, as novas terapias, apesar de transmistirem uma parte da herança psicanalítica, teriam sua filiação negada por seus 'pais', e, ao mesmo tempo, tenderiam a recusá-la (ver CASTEL R., ibidem, p. 164). 
do núcleo central, do movimento? Quem são essas pessoas que, apesar disso, conseguem se transformar de excluídos em 'excluidores'?

Para responder a essas perguntas, levantei a história de vida e a trajetória profissional de vinte terapeutas corporais, doze dos quais fazem parte do núcleo pioneiro do movimento. ${ }^{9}$

Logo de início, me chamou atenção a visível afinidade entre esta nova ocupação e a trajetória dos sujeitos envolvidos no seu surgimento.

Como principal característica dessa trajetória observei uma marcante mobilidade geográfica e social - uma, na verdade, levando à outra. De um lado buscava-se a mobilidade ascendente na escala social através de um diploma universitário. Com apenas duas exceções, nenhum dos sujeitos pesquisados tinha pai ou mãe com diploma superior. Tratava-se, portanto, de buscar alguma coisa que faltava à família de origem e, com isso, mudar seu próprio destino social. Por outro lado, estudar significava, muitas vezes, distanciar-se fisicamente do universo de origem. Dos vinte terapeutas pesquisados, apenas seis são naturais do Rio. Alguns dos participantes do núcleo pioneiro, vindos de pequenas cidades do interior, ${ }^{10}$ relatam uma 'viagem' com várias 'escalas' antes de chegar à cidade grande:

$-A$, natural do interior de Goiás, termina seus estudos secundários em Goiânia, faz o curso de medicina em Manaus e o internato no Rio, onde acaba por se estabelecer;

$-B$, nascida no interior de Minas, faz a faculdade em Belo Horizonte; depois de formada, passa alguns anos em Salvador, onde tem o primeiro contato com técnicas corporais, e vem morar no Rio em 1976;

$-C$, natural do interior do Espírito Santo, faz o curso de psicologia em Belo Horizonte e vai morar em Juiz de Fora, passando a vir ao Rio com frequiência; se especializa em terapia reichiana no México;

Mesmo para aqueles vindos de uma cidade grande, permanece a idéia de um 'descentramento': dois dos pioneiros vindos de São Paulo são filhos de estrangeiros, imigrantes expulsos de seu país de origem pela guerra.

9 Dos oito restantes, três são fundadores de instituições de formação em diferentes modalidades de terapia corporal e outros dois lideram o treinamento em dois tipos de práticas corporais não terapêuticas. Portanto, embora não façam parte do núcleo pioneiro, participaram de forma decisiva na implantação e na difusão das terapias corporais no meio 'psi'.

10 Quatro vieram de pequenas cidades do interior; dois de cidades da periferia do Rio; dois de São Paulo e dois são naturais de outros estados, mas vieram para o Rio ainda pequenos. 
Dois depoimentos colhidos revelam o grau de 'mudança de mundos' que o distanciamento físico pode representar:

"Vim para cá, fiz, passei, e a faculdade realmente mudou minha vida. Foi talvez um dos momentos mais incríveis que eu já passei na minha vida. Eu ficava de manhãa à noite na faculdade. Eu adorei aquele meio. Eu vim de Nova Iguaçu, aquela repressão, sexualidade presa, o contato mesmo com as meninas é um negócio clube do bolinha. Cheguei naquele bolo de mulher, as pessoas falando tudo, vivendo tudo (...) Aquela explosão. Eu tinha participado um pouco do movimento do vestibulando, mas na faculdade... aquele contato, as pessoas estudando, aprendendo, experienciando, vivendo... foi uma loucura na minha vida."

"Aí, nesse ínterim aconteceu uma grande mudança na minha vida, que eu me casei muito jovem (...) Ele era um intelectual de esquerda, militante na ocasião, e ele começou a fazer a minha cabeça (...) Dentro do script de onde eu venho era: ser professora primária, casar e ter filhos, essa era a figuração da vida de uma mulher, no máximo. Só que com esse homem teve toda uma abertura na minha cabeça (...) E discutia toda a política de Fidel Castro. E eu ficava assim... parecia um conto de fadas. Muitas vezes eu dormia embalada por aqueles contos estranhos, eu nunca tinha ouvido falar dessas terras, dos canaviais, eu ficava imaginando essas coisas todas e o máximo de comparação que eu fazia era comparar com Monteiro Lobato que eu tinha lido. Foi uma viagem mesmo, sair desse lugar e ir para um meio onde as pessoas conversavam, discutiam, falavam, liam sobre todos os lugares..."

Mais do que um movimento de baixo para cima, a mobilidade dos sujeitos me pareceu consistir num deslocamento da margem (periferia) para o centro. Margem geográfica e social. Todos os pioneiros, sem exceção, vêm de famílias com poucos recursos financeiros. Os pais são pequenos comerciantes, funcionários públicos, às vezes mesmo pequenos lavradores ou motoristas. Todos com primeiro ou segundo grau. Para os filhos desse universo familiar, a busca do diploma universitário parece ter patrocinado um duplo afastamento geográfico e social - corporificando a esperança de ascensão social.

No texto em que propõe uma diferença entre prestígio e ascensão social, Gilberto Velho afirma ter encontrado "constantemente, em historias de vida e relatos familiares o padrão do indivíduo que sai de seu grupo de origem, cidade, bairro, para explorar novas possibilidades". ${ }^{11}$ Mais abaixo afirma: "O sucesso traduzido em dinheiro e/ou diploma é a ascensão social que pode conferir um novo tipo de prestígio". ${ }^{12}$ É o dilema, comum nos estratos médios de nossa

11 VELHO G., "Prestígio e ascensão social, dos limites do individualismo na sociedade brasileira", in Individualismo e cultura. Rio de Janeiro, Zahar, 1981, pp. 47-48.

12 VELHO G., ibidem, p. 48. 
sociedade, entre permanecer (vinculado ao universo de origem) e mudar (buscando oportunidades de vida inexistentes nesse universo).

$\mathrm{O}$ grupo que pesquisei optou, decididamente, pela mudança. Uma mudança que parece ter seguido uma inclinação familiar. Usamos aqui o termo 'inclinação' no sentido que lhe deu Bourdieu: 'L'habitus petit-bourgeiois est la pente de la trajectoire sociale, individuelle ou collective, devenue penchant par où cette trajectoire ascendante tendà se prolonger et s'accomplir, sorte de nisus perseverandi, comme disait Leibniz, où le trajet passé se conserve sous la forme d'une tension vers l'avenir qui le prolonge..."13 Vários entrevistados referiram-se à importância concedida aos estudos pelos pais, vontade de proporcionar aos filhos a oportunidade que eles - pais - não haviam tido:

“...porque eu fui criada para ir embora. A cidade era uma cidade muito pequena, com muito pouco recurso intelectual, né (...) A mamãe, apesar de ter sido uma mulher que foi criada só lá no interior e nunca saiu de lá - veio a sair mais tarde - ela sempre teve assim muito incentivo, para que a gente não vivesse a história parecida com a dela. Ela queria que a gente progredisse..."

"De uma maneira geral, meu pai passou sempre uma coisa, eu não tenho dinheiro, o que eu posso dar para vocês sendo militar (era de onde vinha a grana dele na verdade) - eu tenho que dar estudo. Então, mesmo lá, a gente estudava nos melhores colégios..."

A inclinação estava lá, transformada em tendência, apontando em direção ao centro - para longe da periferia geográfica e social. Mas que centro é esse? E, sobretudo, como chegar lá?

Se os sujeitos se viam de alguma forma empurrados para longe do universo de origem, a inclinação que os empurrava nada mais era que isso: uma inclinação, uma tendência. As indicações do que fazer para chegar lá - e, até mesmo, onde era o "lá" - eram pouco precisas, quando não inexistentes. Mesmo a expectativa de que os filhos cursassem uma universidade era genérica e pouco específica quanto à carreira a ser seguida.

Vi-me, então, frente a sujeitos cujo destino, ou inclinação, era se tornarem diferentes. Não tanto do que deveriam ser, porque, na verdade, o 'dever ser' desse tipo de trajetoria é exatamente se diferenciar. As orientações vindas do universo de origem eram precárias e teriam, na verdade, que ser abandonadas já que a inclinação da trajetória implicava, necessariamente, o distanciamento desse universo e de suas orientações.

13 BOURDIEU P., La distinction. Paris, Minuit, 1979, p. 387. 
A escolha profissional tinha essa característica paradoxal: ser, ao mesmo tempo, crucial e indefinida.

A maioria dos sujeitos que compõem o grupo pesquisado acaba escolhendo uma carreira com alto grau de indeterminação e abertura: a psicologia. Uma ocupação ainda nova, ${ }^{14}$ em expansão, com múltiplas possibilidades de atuação e que, por isso mesmo, não implicava qualquer exclusão a priori. Mesmo no caso dos sujeitos que optaram pela medicina (três entre os doze que formam o 'núcleo pioneiro'), tratava-se de explorar exatamente seus pontos de indeterminação, voltando-se para as chamadas 'medicinas alternativas' ou para, no interior da psiquiatria, práticas psicoterápicas novas - campos que, por estarem em expansão e serem relativamente marginais, tendem mais a incluir os recém-chegados do que a excluí-los.

$\mathrm{Na}$ sua caminhada das margens para $\mathrm{o}$ centro, os sujeitos acabam, portanto, fazendo uma escolha ocupacional razoavelmente marginal, isto é, aparentemente distante do 'centro'. Pela psicologia e, dentro da psicologia, pelas práticas que floresciam em torno do núcleo formado pelas teorias respeitáveis e bem estabelecidas - isto é, nas suas margens.

Trata-se de um grupo formado por pessoas que, por causa de seu background social, tinham poucas chances de ser absorvidas no núcleo de maior prestígio de qualquer profissão. A difusão da psicanálise as atrai para a órbita mais ampla da psicologia. ${ }^{15}$ Em primeiro lugar pelo alto grau de indeterminação e abertura que é capaz de oferecer, mas também porque contém em si a promessa de uma definição, ao mesmo tempo, profissional e pessoal. Lembramos que esses sujeitos se diferenciam, se afastam do universo de origem, exatamente através da escolha profissional. É porque vão para a universidade que o afastamento se torna ao mesmo tempo necessário e inevitável. Esse afastamento, lembramos, nunca apenas físico, mas sempre necessariamente simbólico, porque implica deixar para trás - e mesmo negar — todo um modo de vida e um universo de valores. A trajetória dos sujeitos é construída, na verdade, a partir dessa negação - 0 'ser diferente'. Ora, esse 'ser diferente', ao mesmo tempo, não pode ser construído tendo como base somente a negação. $\mathrm{O}$ distanciamento do universo original de valores significa a adoção (ou a .

14 A profissão de psicólogo só foi regulamentada no Brasil em 1962.

15 Lembrando nosso argumento inicial, é importante frisar que a maior parte dos cursos de psicologia hoje existentes foi criada no rastro da difusão psicanalítica dos anos 70. A atração exercida pela psicologia não deixava, portanto, de fazer parte dessa difusão, que sem dúvida se distanciava cada vez mais de seu centro. 
construção) de algum outro, a partir do qual a trajetória que o sujeito se vê percorrendo adquire sentido.

A psicologia propicia, ao mesmo tempo, a possibilidade de uma ocupação rentável (capaz de distanciar os sujeitos e a sua origem social) e, o que talvez seja mais importante, a possibilidade de um encontro consigo mesmo através dessa ocupação rentável. Propicia a almejada mobilidade social e, no mesmo ato, lhe dá sentido.

Dentro do campo 'psi', as terapias corporais - que começavam a ser valorizadas exatamente pelo que tinham de marginais - significaram, para essas pessoas, a possibilidade de transformar seu handicap em vantagem, fornecendo um ideário capaz de sustentar essa transformação.

As terapias corporais, calcadas em maior ou menor grau na teoria reichiana, partem de uma oposição radical entre indivíduo e sociedade. $O$ indivíduo concebido como algo anterior à sociedade, e esta sendo vista como o que impede a expressão dos impulsos naturais desse indivíduo pré-social. Daí privilegiar o trabalho com o corpo, sede dos impulsos e instintos naturais. A palavra - enquanto representante da racionalidade - significa o distanciamento da emoção e dos impulsos. A palavra está do lado da sociedade e, por isso, deve ser ultrapassada. A capacidade de verbalizar perde importância porque distancia o homem dos outros seres naturais:

"Les concepts de la psychologie traditionelle et de la psychologie des profondeurs sont indissolublement liés à des formations verbales. Mais les fonctions de la vie dépassent toutes les idées et tous les concepts fondés sur des mots. Le langage verbal est une forme d'expression biologique hautement évoluée. Mais il n'est en aucune manière un atribut indispensable de la matière vivante, puisque les fonctions vitales existent longtemps avant le langage. La psychologie des profondeurs travaille donc sur une fonction d'origine recente. Beaucoup d'animaux s'expriment par des sons. Mais la matière vivante fonctionne avant et au-déla de toute formation de sons comme forme de expression."16

A concepção de natural, espontâneo, biológico e, por isso, corporal, se opõe à artificialidade da sociedade (e à racionalidade da palavra). A palavra pode esconder as verdadeiras emoções e sentimentos. $\mathrm{O}$ corpo, não.

É através do corpo que se chega à pessoa 'como ela é naturalmente'. A idéia de que há uma pessoa natural atrás das máscaras 'impostas' pela sociedade é exatamente o que cauciona a transformação de que falávamos.

16 REICH W., “Análise do caráter”, citado in HIGGINS M. e RAPHAEL M. (orgs.), Reich parle de Freud. Paris, Payot, 1972, p. 43. 
O que caracteriza o grupo estudado é a luta contra seu provável destino social. O esforço para superar as limitações de sua origem social e as possibilidades que esta oferecia. São pessoas que, nesse sentido, se fazem a si mesmas, contra as barreiras colocadas em seu caminho pela sociedade. Pessoas que constróem sua trajetória de forma absolutamente individual — trabalhando como office-boy ou baby-sitter, 'cavando' empregos e bolsas de estudo, vendendo tudo para se especializar no exterior, sem qualquer possibilidade de ajuda financeira ou de 'influência' vinda da família de origem. Sua história de vida fornece, portanto, a imagem concreta do indivíduo que, fazendo-se sozinho, vence os limites impostos pela sociedade - que, por seu lado, 'limita' e 'reprime'.

O ideário das terapias corporais lhes permite transformar essa luta contra determinadas barreiras sociais numa luta contra o social como um todo. Empresta à mesma um significado que transcende a questão pura e simples de 'subir na vida' ou 'progredir'.

Ao mesmo tempo, a ácida crítica ao 'sistema social' que impede o desenvolvimento pleno e saudável do indivíduo lhes permite inverter o processo de exclusão que os teria condenado a uma vida marginal ao centro procurado. Não é o 'sistema' que não os quer. Eles é que o rejeitam. A marginalidade esse viver nas margens e pelas bordas, que um dos entrevistados define como 'um andar meio esquerdo na vida' - é transformada de defeito em virtude, de problema a ser resolvido em vantagem a ser auferida.

Por outro lado, já vimos que a necessidade de distanciamento - e conseqüente negação - do universo de origem implica a adoção de novas orientações para a construção da propria identidade. As teorias que servem de base às terapias corporais, por serem psicológicas, são capazes de, ao mesmo tempo, justificar a negação da 'sociedade' (do universo social de origem e das limitações que ele representava) e transformar o 'fazer-se a si mesmo' em autodescoberta. É, na verdade, negando o 'social' que o sujeito descobre a si mesmo.

Essa autodescoberta (ou autoconstrução) se faz através do corpo. A palavra, instrumento básico da racionalidade e da lógica escolar, fica em segundo plano. De novo a ideologia das terapias corporais justifica e dá sentido ao modo como os sujeitos 'se fizeram' pelas margens das instâncias tradicionais de consägração escolar - isto é, de consagração pela palavra - afirmando um outro tipo de consagração paralela, alternativa, que não depende tanto de estudo, diploma, teoria, mas sim de 'vivências', 'exercícios', em suma, de trabalho corporal. 
Esse grupo pioneiro constituiu um campo inicialmente disperso, difuso, no qual as práticas se combinavam um pouco ao gosto do freguês. A maioria fez os mais diversos treinamentos no Brasil e no exterior: em bioenergética, biossíntese, biodinâmica, massagem reichiana, massagem de Esalem, Radix, vegetoterapia, somaterapia (com Roberto Freire) etc. O tratamento que ofereciam a seus clientes e o treinamento que forneciam aos novos terapeutas eram, por isso, quase sempre bastante ecléticos. Ao mesmo tempo, praticamente todos faziam (alguns ainda fazem) terapia psicanalítica como pacientes.

Não havia qualquer definição do direito de entrada e permanência no campo, a não ser o controle informal do próprio grupo. Pessoas não formadas em medicina ou psicologia podiam exercer (como, de resto, exercem até hoje) a função de terapeuta. $O$ treinamento para esse exercício não era ainda objeto de controle e disputa, dependendo das possibilidades, do 'faro' e do empenho pessoal de cada um. Por outro lado, a própria função terapêutica não era claramente definida. Isto é, a fronteira entre terapia e não terapia (as 'vivências', 'maratonas', 'encontros') eram fluidas. Daí, por exemplo, a possibilidade de se fazer bioenergética e psicanálise ao mesmo tempo.

Essa marca do primeiro momento de difusão e florescimento das terapias corporais - a tolerância e a indefinição de fronteiras - não deixa de ser o que marca a própria trajetória do grupo. O caminho da periferia (ou das margens) para o centro é, em si, um processo de diluição de fronteiras. Fronteiras que no início são sociais e depois se tornam profissionais.

Esse processo está em pleno curso, de forma aparentemente invertida. A partir de meados da década de 1980, mas especialmente a partir de 1989, começam a surgir instituições de formação em diferentes linhas de terapia corporal. O processo de institucionalização é liderado (diríamos mesmo provocado) pelas instituições de formação em orgonomia que preconizam uma volta ortodoxa a Reich. No lugar da indefinição tolerante dos primeiros anos, assistimos a uma intensa busca de definição, acompanhada pela construção diligente de fronteiras claras e precisas: entre quem é ou não é terapeuta 'autorizado', entre o que é ou não 'terapia reichiana', entre quem pode ou não pode fazer formação etc.

Dizíamos que o caminho das margens para o centro é um processo de diluição de fronteiras. Isso às vezes é feito de forma paradoxal. Por exemplo, o rígido estabelecimento de fronteiras que hoje assistimos entre os terapeutas corporais não deixa de ser um modo de diluir uma outra fronteira, mais fundamental - a que separa (ou separava) as 'terapias corporais', vistas como um conjunto amorfo de práticas semiprofissionais, das terapias 'respeitáveis' e reconhecidas como tal no campo 'psi'. Ou seja, trata-se, de novo, de atingir 
a fronteira entre o centro e a periferia. E, se não for possível ultrapassá-la, torná-la fluida o suficiente para que a certeza dos que se consideram no centro ceda lugar à desconfiança de que as margens, afinal, não estão tão longe assim.

\section{RESUMO}

\section{Tornar-se Terapeuta Corporal: a Trajetória Social como Processo de "Autoconstrução"}

Este artigo trata do surgimento e do florescimento das terapias corporais enquanto possibilidade ocupacional no campo das práticas psicológicas, focalizando especificamente a cidade do Rio de Janeiro. Tem como objetivo demonstrar que existe uma relação entre o surgimento da terapia corporal enquanto ocupação e a trajetória de vida dos pioneiros responsáveis por sua implantação no meio 'psi' carioca.

\section{ABSTRACT}

\section{Becoming a Body Therapist: Social History as a Process of "Self-Construction"}

The article examines the appearance and growth of body therapies as an occupational alternative in the field of psychological practice in the city of Rio de Janeiro. It intends to show that there is a relation between the appearance of body therapy as an occupation and the life histories of those who pioneered the technique within Rio's psychology community.

\section{RESUME}

\section{Devenir Thérapeute Corporel: la trajectoire sociale en tant que processus d" "Autoconstruction"}

Cet article est consacré au surgissement et à l'épanouissement des thérapies corporelles en tant que possibilité professionelle dans le domaine des pratiques psychologiques. Il se concentre tout particulièrement sur la situation de la ville de Rio de Janeiro et a pour but de démontrer qu'il existe une relation entre le surgissement de la thérapie corporelle professionnelle et la trajectoire 
existentielle des pionniers reponsables de son implantation dans le milieu "psy" de Rio de Janeiro. 
